\title{
An Experimental Approach for the Identification of Conserved Secreted Proteins in Trypanosomatids
}

\author{
Rosa M. Corrales, ${ }^{1}$ Françoise Mathieu-Daudé, ${ }^{1}$ Déborah Garcia, ${ }^{1}$ Simone F. Brenière, ${ }^{2}$ \\ and Denis Sereno ${ }^{1}$
}

${ }^{1}$ Département Sociétés et Santé, UR016 Caractérisation et contrôle des populations de vecteurs,
Institut de Recherche pour le Développement, 911 Avenue Agropolis, 34394 Montpellier, France
${ }^{2}$ Département Sociétés et Santé, UR016 Caractérisation et contrôle des populations de vecteurs,
Représentation en Bolivie, Avenue Hernando Siles 5290, Esq Calle 7, Obrajes CP 9214, La Paz, Bolivia

Correspondence should be addressed to Rosa M. Corrales, milagroscorrales@yahoo.com.ar

Received 1 August 2009; Accepted 14 October 2009

Academic Editor: Jorge Morales-Montor

Copyright ( $) 2010$ Rosa M. Corrales et al. This is an open access article distributed under the Creative Commons Attribution License, which permits unrestricted use, distribution, and reproduction in any medium, provided the original work is properly cited.

\begin{abstract}
Extracellular factors produced by Leishmania spp., Trypanosoma cruzi, and Trypanosoma brucei are important in the hostparasite relationship. Here, we describe a genome-based approach to identify putative extracellular proteins conserved among trypanosomatids that are likely involved in the classical secretory pathway. Potentially secreted proteins were identified by bioinformatic analysis of the T. cruzi genome. A subset of thirteen genes encoding unknown proteins with orthologs containing a signal peptide sequence in L. infantum, L. major, and T. brucei were transfected into L. infantum. Tagged proteins detected in the extracellular medium confirmed computer predictions in about $25 \%$ of the hits. Secretion was confirmed for two L. infantum orthologs proteins using the same experimental system. Infectivity studies of transgenic Leishmania parasites suggest that one of the secreted proteins increases parasite replication inside macrophages. This methodology can identify conserved secreted proteins involved in the classical secretory pathway, and they may represent potential virulence factors in trypanosomatids.
\end{abstract}

\section{Introduction}

The Trypanosomatidae comprise a large group of parasitic protozoa, some of which cause important diseases in humans. The organisms that have been most extensively studied are Trypanosoma brucei, the causative agent of African sleeping sickness, T. cruzi, responsible for Chagas disease in South America, and Leishmania spp., which causes Leishmaniasis in Asia, South America, and Mediterranean countries [1]. In order to complete their life cycle, these parasites have to adapt and develop in an insect vector and in a vertebrate host. These single-celled organisms have developed several strategies to modify their surrounding environment, modulate host immune responses, or interfere with the host's anti-microbial activity. Materials secreted by the parasite are involved in these processes helping the parasite survive in an environment more favorable for its own development [2-5]. In addition, previous studies indicate that trypanosomatid secreted factors elicit strong immunity and protection against infection in mice and dogs $[6,7]$. Thus secreted factors could be a source of antigens for vaccine development, as demonstrated in the pathogen Mycobacterium tuberculosis [8]. Nevertheless, all trypanosomatid secreted factors involved in virulence and/or representing putative vaccine targets are not currently known.

The availability of three draft trypanosomatid genome sequences provides valuable data for protein-mining using bioinformatic tools, especially for the localization or prediction of function for hypothetical proteins. Given that a significant number of trypanosomatid protein-coding genes are annotated as hypothetical, additional studies are needed to ascertain their function.

In the present study, we designed an experimental genome-based approach to identify potentially secreted proteins that are conserved among the three main trypanosomatid pathogens and involved in the classical secretory pathway. We hypothesized that a phylogenetic conservation 
among Leishmania, T. cruzi, and T. brucei would indicate evolutionary selection for this family of proteins and suggest an important role for such secreted proteins in the biology of these parasites. Our results demonstrate that the bioinformatic analysis, combined with the functional tests, provides a useful and reliable method for the identification of novel secreted proteins, representing potential virulence factors in trypanosomatids. The results are also discussed in relation to the relative importance of the classical and nonclassical secretory pathways for the release of proteins into the extracellular environment.

\section{Materials and Methods}

2.1. In Silico Sequence Analysis. Release V 5.0 of the $T$. cruzi genome was extracted from the integrated T. cruzi genome resource TcruziDB (http://tcruzidb.org/tcruzidb/). Protein sequences that do not bear an initial methionine amino acid were removed manually. Proteins belonging to large families of surface molecules, which include transsialidases, mucins, gp63s, and mucin-associated surface proteins, were also discarded. Finally ORFs encoding proteins bearing a molecular weight (MW) above 90 $\mathrm{kDa}$ were also eliminated. The software SignalP 3.0 (http://www.cbs.dtu.dk/services/SignalP/) was used to predict the presence of a signal peptide and a cleavage site in amino acid sequences [9]. Protein sequences having a signal peptide probability greater than 0.8 associated with a cleavage site probability greater than 0.7 were analyzed for the presence of orthologs in the related Trypanosoma brucei and Leishmania major parasite genomes predicted by Jaccard COG clustering in Gene DB (http://www.genedb.org/). Most of these orthologs were confirmed in TriTrypDB (http://tritrypdb.org/tritrypdb/) using OrthoMCL and genomic context analysis (gene synteny). The TMHMM 2.0 (http://www.cbs.dtu.dk/services/TMHMM/) and the DAS-TMfilter (http://mendel.imp.ac.at/DAS/source.html) servers were used for the prediction of transmembrane helices in protein sequences.

2.2. Parasite Strains and Cultures. The T. cruzi TcY7 (or Y cl7) clone derived from the Y strain [10] was used throughout this study. Epimastigotes were grown in liver infusion tryptose (LIT) medium supplemented with 10\% FCS at $28^{\circ} \mathrm{C}$ in standard conditions [11] and harvested during the logarithmic growth phase. Metacyclic trypomastigotes, obtained from the differentiation of late stationary phase epimastigotes, were used to initiate infection of mouse fibroblasts (L929). Trypomastigotes and amastigotes were produced and harvested as previously described [12]. Pellets for RNA purification were processed immediately in lysis buffer. The wild-type (WT) promastigote clone from $L$. infantum (MHOM/MA/67/ITMAP-263) was maintained at $26^{\circ} \mathrm{C}$ by weekly subpassages in SDM 79 medium supplemented with $10 \%$ heat-inactivated FCS, $100 \mathrm{U} / \mathrm{mL}$ penicillin, and $100 \mu \mathrm{g} / \mathrm{mL}$ streptomycin [13].

2.3. Reverse Transcription and PCR Amplifications. Total RNA was extracted from epimastigotes, amastigotes, and trypomastigotes with the RNeasy kit (Qiagen, Hilden, Germany) according to the manufacturers' instructions, and treated with DNase I (DNA-free kit, Ambion Inc., Austin, Texas). Reverse transcription was performed for $1 \mu \mathrm{g}$ of total RNA using random hexamers and Superscript II reverse transcriptase (Invitrogen, Carlsbad, CA) according to the manufacturers' instructions. The cDNA $(4 \mu \mathrm{L}$ of $1 / 10$ dilutions) from each stage was amplified by PCR in a $20 \mu \mathrm{L}$ reaction volume using $10 \mu \mathrm{L}$ of $2 \mathrm{X}$ PCR Master Mix $1 \mathrm{X}$ (Promega, Madison, Wisconsin) and $0.5 \mu \mathrm{M}$ gene-specific forward and internal reverse primers (listed in Table 1) using the following cycling conditions: $94^{\circ} \mathrm{C}$ for 3 minutes followed by 30 cycles of $94^{\circ} \mathrm{C}$ for 30 seconds, $55^{\circ} \mathrm{C}$ to $58^{\circ} \mathrm{C}$ (according to the primer pair) for 30 seconds, $72^{\circ} \mathrm{C}$ for 45 seconds, and a final elongation at $72^{\circ} \mathrm{C}$ for 5 minutes. Amplicons were electrophoresed on $2 \%$ agarose gels stained with ethidium bromide.

2.4. Cloning and Sequencing. The encoding genes selected by in silico analysis were cloned into the pTEX expression vector, carrying the Neomycin resistance gene (NEO) [14]. Full length ORFs were amplified from genomic DNA with specific reverse and forward primers, including different restriction sites and a 6-Histidine-Tag in the C-terminal region (listed in Tables 1 and 3). PCR reactions were carried out in $20 \mu \mathrm{L}$ using $0.5 \mu \mathrm{M}$ of each primer, $0.2 \mathrm{mM}$ dNTP, $0.4 \mathrm{U}$ of Phusion high-fidelity polymerase (Finnzymes, Espoo, Finland), and the following cycling conditions: $98^{\circ} \mathrm{C}$ for 30 seconds followed by 25 cycles of $98^{\circ} \mathrm{C}$ for 10 seconds, $64^{\circ} \mathrm{C}$ to $68^{\circ} \mathrm{C}$ for 15 seconds, $72^{\circ} \mathrm{C}$ for 25 to 60 seconds (according to gene size), and a $72^{\circ} \mathrm{C}$ elongation for 5 minutes. Digested and purified fragments were inserted into the dephosphorylated pTEX vector digested with the corresponding restriction enzymes. Cloned sequences were confirmed by restriction digestion and sequencing. Large-scale preparations of the different constructs were performed using the Plasmid Midi kit (Promega).

2.5. Transfection Procedures. Promastigotes of the Leishmania infantum clone were electroporated as described elsewhere [15]. Briefly, promastigotes were washed twice with HEPES-NaCl buffer saline $(21 \mathrm{mM}$ HEPES, $5 \mathrm{mM}$ $\mathrm{KCl}, 0.7 \mathrm{mM} \mathrm{NaH} \mathrm{PO}_{4}, 137 \mathrm{mM} \mathrm{NaCl}$ ), resuspended at $10^{8}$ cells $/ \mathrm{mL}$ in HEPES-NaCl electroporation buffer $(\mathrm{pH}$ 7.2) supplemented with $6 \mathrm{mM}$ glucose and cooled on ice for 10 minutes. Cells $\left(10^{8}\right)$ were combined with $15 \mu \mathrm{g}$ of vector, left on ice for 10 additional minutes, and electroporated using an Easyject Plus (Eurogentec, Seraing, Belgium) apparatus set at $450 \mathrm{~V}$ and $450 \mu \mathrm{F}$, for one pulse. The cells were left on ice for a further 10 minutes and transferred to $4 \mathrm{~mL}$ of growth medium. The antibiotic G$418(20 \mu \mathrm{g} / \mathrm{mL})$ was added 24 hours later, and parasites were subcultured at a dilution of $1 / 10$ in $5 \mathrm{~mL}$ SDM in the presence of $20 \mu \mathrm{g} / \mathrm{mL}$ G418. Drug-resistant cells were observed 15-20 days later. Parasites were grown in the presence of gradually increasing concentrations of G418 and were routinely maintained in SDM containing $150 \mu \mathrm{g} / \mathrm{mL}$ of G418. 
TABle 1: Primer pairs designed to amplify the genes encoding the 13 T. cruzi putative secreted proteins conserved in trypanosomatids and T. cruzi Tubulin (negative control).

\begin{tabular}{|c|c|c|c|}
\hline T. cruzi GeneDB Gene ID No. & Primer sequences $^{(a)}$ & $\begin{array}{l}\mathrm{F} / \text { Rint and } \mathrm{F} / \mathrm{R} \\
\text { product sizes (bp) }\end{array}$ & $\operatorname{MW}(\mathrm{kDa})^{(\mathrm{b})}$ \\
\hline \multirow{3}{*}{ Тc00.1047053506417.30 } & $\begin{array}{l}\text { F CATGAGCTTACTAGTATGTTGTCT } \\
\text { CTGGCAGAAGTGTGT }\end{array}$ & & \\
\hline & Rint ACGGTGCCCAAAGGCGTGTA & 311 & \\
\hline & $\begin{array}{l}\text { R CACACGGAAGCTTTCAATGATGATGAT } \\
\text { GATGATGGCGACCAAACCTAGCCATAAG }\end{array}$ & 705 & 25.7 \\
\hline \multirow{3}{*}{ Тc00.1047053506155.99 } & $\begin{array}{l}\text { F CTGGGGGAATTCATGCGGTGG } \\
\text { ATTTTTTTGTTACTTGCC }\end{array}$ & & \\
\hline & Rint CCGATACGTCCACCACCCCTC & 336 & \\
\hline & $\begin{array}{l}\text { R CGTCGGAAGCTTCTAGTGATGGTGGTG } \\
\text { GTGATGGACAAGTTCGTGGCATGTAATTG }\end{array}$ & 735 & 28.1 \\
\hline \multirow{3}{*}{ Тc00.1047053506467.29 } & $\begin{array}{l}\text { F ACACGGACTAGTATGATTG } \\
\text { TATTGAATGGAATTTCTGAG }\end{array}$ & & \\
\hline & Rint CTAATAGTCCGAAGTCGTTGCG & 309 & \\
\hline & $\begin{array}{l}\text { R CTACACAAGCTTTTAGTGATGGTGATG } \\
\text { GTGATGGCTGCGCCTCCACACCGTGC }\end{array}$ & 1065 & 39.7 \\
\hline \multirow{3}{*}{ Тс00.1047053511901.30 } & $\begin{array}{l}\text { F CTGATAGGCACTAGTATGTTTC } \\
\text { CGGCGCAGGAATTCCT }\end{array}$ & & \\
\hline & Rint CCCCTTTCAGGTGACCATTACAAGAG & 316 & \\
\hline & $\begin{array}{l}\text { R GCCGTCAAGCTTTTAGTGGTGGTGGTG } \\
\text { GTGATGCTCCGCTCCCAACTTCAAACGA }\end{array}$ & 1041 & 39.8 \\
\hline \multirow{3}{*}{ Тc00.1047053511871.30 } & $\begin{array}{l}\text { F CTGATAGGCACTAGTATGCGTC } \\
\text { GCACTTTATTTTGTCTG }\end{array}$ & & \\
\hline & Rint CTCTCCAACTCGTACGGCGA & 305 & \\
\hline & $\begin{array}{l}\text { R CTGCAGGCAAGCTTCTAATGGTGGTGATG } \\
\text { GTGATGTTATGATACCGGCATCAAGTCCCC }\end{array}$ & 1269 & 47.0 \\
\hline \multirow{3}{*}{ Тc00.1047053505789.10 } & $\begin{array}{l}\text { F CGCACTCACTAGTATGCCCTCT } \\
\text { GGCAAAGCAACTG }\end{array}$ & & \\
\hline & Rint TCACTGCTCCGCCCTGGTTTC & 308 & \\
\hline & $\begin{array}{l}\text { R CGCTCCCTCGAGTTAGTGGTGATGGTGGTG } \\
\text { ATGGGCAGCATTTACCGACCCTGA }\end{array}$ & 1488 & 53.6 \\
\hline \multirow{3}{*}{ Тc00.1047053509669.70 } & $\begin{array}{l}\text { F GCTCAGCCAAGCTTATGCG } \\
\text { CACTTCTTCTGCCGTGT }\end{array}$ & & \\
\hline & Rint ATCGGGGAGTTTTGTGCAGGTTGAG & 322 & \\
\hline & $\begin{array}{l}\text { R GTGGTCTTCTCGAGTTAGTGATGGTGGTG } \\
\text { GTGATGGTCGACTTTAATGCTCGCGTATA }\end{array}$ & 1944 & 73.1 \\
\hline \multirow{3}{*}{ Тc00.1047053507765.20 } & $\begin{array}{l}\text { F CTGCCCAGTACTAGTATGT } \\
\text { CTGCTAAAGCCTCACGGC }\end{array}$ & & \\
\hline & Rint TCCAGGTAGTCACCCATTCCGTG & 318 & \\
\hline & $\begin{array}{l}\text { R CTCAGCCAAGCTTTTAATGATGATGATG } \\
\text { ATGGTGTCGTCTCGCCTCACAGTGCT }\end{array}$ & 1521 & 57.2 \\
\hline \multirow{3}{*}{ Тс00.1047053510101.470 } & $\begin{array}{l}\text { F CTGCGCTGGACTAGTATG } \\
\text { TCTGTTAAAGCCTCACGGCG }\end{array}$ & & \\
\hline & Rint CCATTCCGTGACCGCCGTAGAC & 302 & \\
\hline & $\begin{array}{l}\text { R CTCGGTAAGCTTTTAATGATGATGATG } \\
\text { ATGGTGTCGTCTCGCCTCACAGTGCT }\end{array}$ & 1518 & 57.3 \\
\hline \multirow{3}{*}{ Тc00.1047053510443.30 } & $\begin{array}{l}\text { F CTCGCTGGAATTCATGCGGTGG } \\
\text { GTGATAGTTGTATTTGC }\end{array}$ & & \\
\hline & Rint CGCCAACAACGTAGTTGCCAAG & 313 & \\
\hline & $\begin{array}{l}\text { R ACGGACCTCGAGTTAGTGATGGTGGTG } \\
\text { GTGATGCTTGTTGAGTTTGGAGCGGCG }\end{array}$ & 612 & 23.0 \\
\hline
\end{tabular}


TABle 1: Continued.

\begin{tabular}{|c|c|c|c|}
\hline T. cruzi GeneDB Gene ID No. & Primer sequences $^{(\mathrm{a})}$ & $\begin{array}{c}\mathrm{F} / \mathrm{Rint} \text { and } \mathrm{F} / \mathrm{R} \\
\text { product sizes }(\mathrm{bp})\end{array}$ & $\mathrm{MW}(\mathrm{kDa})^{(\mathrm{b})}$ \\
\hline \multirow{4}{*}{ Tc00.1047053509799.50 } & F CGCGGGACTAGTATGAAACAA & & \multirow[b]{4}{*}{26.5} \\
\hline & AAAATGCGACGCAAATTG & & \\
\hline & Rint GTGAGGATGGGGAACCAAAAGAGTC & 297 & \\
\hline & $\begin{array}{l}\text { R CAGCCAAGCTTCTAGTGATGGTGATGATG } \\
\text { ATGGACATTCTTCTTCTTTGTAAAGTAG }\end{array}$ & 687 & \\
\hline \multirow{3}{*}{ Tc00.1047053509835.30 } & $\begin{array}{l}\text { F CGCGGCACTAGTATGTATT } \\
\text { CATGTTTGTCGCTGAGGC }\end{array}$ & & \multirow[b]{3}{*}{71.6} \\
\hline & Rint GCAGCAACGGCAACAAAGAGC & 324 & \\
\hline & $\begin{array}{l}\text { R CATGGCAAGCTTTTAGTGATGGTGGTG } \\
\text { GTGATGCTCCTCT CTGGGTTTCCTTCG }\end{array}$ & 2031 & \\
\hline \multirow{3}{*}{ Tc00.1047053509999.10 } & $\begin{array}{l}\text { F CGCGCCACTAGTATGTACG } \\
\text { TCGTGCTTTTTTTCGTTT }\end{array}$ & & \multirow[b]{3}{*}{46.6} \\
\hline & Rint CGCATATTTCCGCTCCGTTCC & 305 & \\
\hline & $\begin{array}{l}\text { R AGCAGTCCAAGCTTTTAGTGATGGTG } \\
\text { ATGATGATGGCCGCACCAGCGCTCCAGAA }\end{array}$ & 1227 & \\
\hline \multirow{3}{*}{ Tc00.1047053506563.40 (c) } & $\begin{array}{l}\text { F GGGTGCCACTAGTATGCGT } \\
\text { GAGATTGTGTGCGTTCAG }\end{array}$ & & \multirow{3}{*}{49.6} \\
\hline & Rint GGGCGGAAGATCTGCCCGTATG & 259 & \\
\hline & $\begin{array}{l}\text { R AGCGCTCAAGCTTTTAGTGATGGTGGTG } \\
\text { GTGATGGTACTGCTCCTCCTCGTCGAACT }\end{array}$ & 1329 & \\
\hline
\end{tabular}

2.6. PCR Amplifications in Transfected Parasites. PCR amplifications were carried out to check for the presence of the NEO gene and the corresponding gene in transfected parasites. A fragment of $800 \mathrm{bp}$ corresponding to the NEO gene was amplified with specific forward and reverse primers (F5' ATGATTGAACAAGATGGATTGCACGCAGG 3', R5' TCAGAAGAACTCGTCAAGAA 3'). Full length ORFs of the specific genes were amplified with primers listed in Table 1. PCR reactions were carried out in a $20 \mu \mathrm{L}$ reaction volume using $10 \mu \mathrm{L}$ of Master Mix 1X (Promega, Madison, Wisconsin) and $0.5 \mu \mathrm{M}$ NEO and gene-specific forward and reverse primers using the following cycling conditions: $94^{\circ} \mathrm{C}$ for 3 minutes followed by 30 cycles of $94^{\circ} \mathrm{C}$ for 30 seconds, $55^{\circ} \mathrm{C}$ to $58^{\circ} \mathrm{C}$ (according to the primer pair) for 30 seconds, $72^{\circ} \mathrm{C}$ for 45 seconds to 2 minutes (according to gene size), and a final elongation at $72^{\circ} \mathrm{C}$ for 5 minutes.

2.7. Production of Cell-Free Culture Supernatants. To analyze the presence of secreted proteins in the supernatant, $1 \times$ $10^{9} \mathrm{~L}$. infantum promastigotes from log-phase culture were collected by centrifugation, washed twice in HEPES-NaCl buffer, resuspended in $40 \mathrm{~mL}$ of HEPES-NaCl ( $\mathrm{pH} 7.2$ ), $11 \mathrm{mM}$ glucose, $200 \mu \mathrm{g} / \mathrm{mL} \mathrm{G}-418$, and incubated for 6 hours at $27^{\circ} \mathrm{C}$. Parasite viability was then assessed as previously described [16] and harvested by centrifugation at 2,100 $\mathrm{g}$ for 10 minutes at $4^{\circ} \mathrm{C}$. The parasite pellet was stored at $-80^{\circ} \mathrm{C}$ for subsequent SDS-PAGE analysis and the supernatant was filtered through a low retention $0.45 \mu \mathrm{m}$ PVDF filter membrane (Millipore, Boston, Massachusetts). After addition of protease inhibitor cocktail (Sigma-Aldrich) the filtrate was concentrated up to 80 -fold using an Ultra-Centrifugal Filter device, according to manufacturers' instructions (Amicon Bioseparations, MilliporeCorp). The concentrated cell-free culture supernatant was frozen and stored at $-80^{\circ} \mathrm{C}$.

2.8. Production of Parasite Lysates. Cell pellets of wildtype and episomally transfected L. infantum promastigotes were resuspended in RIPA buffer $(25 \mathrm{mM}$ Tris- $\mathrm{HCl} \mathrm{pH} 7.6$, $150 \mathrm{mM} \mathrm{NaCl}, 1 \%$ NP-40, 1\% Sodium deoxycholate and $0.1 \%$ SDS), incubated on ice for 30 minutes and sonicated three times for 20 seconds. The soluble phase was recovered by centrifugation at $10,000 \mathrm{~g}$ for 30 minutes $\left(4^{\circ} \mathrm{C}\right)$ and the protein concentration was determined using a Bradford protein assay (Bio-Rad Laboratories, Hercules, California).

2.9. Gel Electrophoresis and Western Blot Analysis. Proteins from parasite lysates $(35 \mu \mathrm{g})$ or from $80 \times$ concentrated cellfree supernatants $(2 \mu \mathrm{g})$ were separated on an NuPAGE BisTris gel $(4 \%-12 \%)$ in MOPS-SDS running buffer (Invitrogen) under reducing conditions (50 mM DTT) and transferred to a PVDF membrane (Hybond-P, Amersham). The membrane was rinsed twice in TBS and incubated for 1 hour in the anti-His HRP conjugate blocking buffer (Qiagen). The membrane was then incubated in 1/3000 anti-His HRP conjugate antibody (Qiagen) for 1 hour and washed seven times for 5 minutes in TBS-T buffer (TBS-0.5 \% Tween 20). Signals were detected by chemiluminescence emission using 
the ECL Plus Western blotting detection system and ECL Hyperfilms (GE Healthcare, UK).

2.10. Generation of Bioluminescent L. Infantum Promastigotes and In Vitro Infection of Human Macrophages. A homologous episomal expression system was devised to further examine the infection in vitro of two secreted proteins from $L$. infantum. The vector pSP- $\alpha \mathrm{HYG} \alpha \mathrm{LUC}$ [17] carrying the firefly-luciferase gene was used to cotransfect $L$. infantum promastigotes overexpressing the secreted proteins LinJ19.0410 (ortholog of Tc00.1047053505789.10) or LinJ36.5780 (ortholog of. Tc00.1047053506155.99). Recombinant parasites were selected for their growth in increasing concentrations of Hygromycin (up to $300 \mu \mathrm{g} / \mathrm{mL}$ ) over a period of several weeks. Promastigotes transfected with the pTEX vector alone and the pSP- $\alpha \mathrm{HYG} \alpha \mathrm{LUC}$ were used as controls for infection experiments. The survival of transfected parasites was evaluated within human leukemia monocyte cells (THP-1 cells). THP-1 cells were cultured in RPMI 1640 medium supplemented with 10\% FCS, $2 \mathrm{mM}$ glutamine, $100 \mathrm{IU}$ of penicillin/mL, and $100 \mu \mathrm{g}$ of streptomycin $/ \mathrm{mL}$. THP- 1 cells in the log-phase of growth were differentiated into macrophages by incubation for 2 days in a medium containing $20 \mathrm{ng} / \mathrm{mL}$ of phorbol myristate acetate (Sigma-Aldrich). THP-1 cells treated with PMA were washed with prewarmed medium and then infected with stationary-phase promastigotes of transfected-Leishmania in a 24-well plate at a parasite/macrophage ratio of $10: 1$ for 4 hours at $37^{\circ} \mathrm{C}$ with $5 \% \mathrm{CO}_{2}$. Noninternalized parasites were removed. After different incubation periods (24 hours to 96 hours) Luciferase activity was determined using the Steady Glo reagent (Promega, Madison,WI), according to the manufacturers' instructions. After 5 minutes, the plate was read using a Multilabel Counter VICTOR ${ }^{2}$ model 1420 (Perkin Elmer). Results are expressed as the mean of RLU (Relative Luminescence Units) activity of three independent experiments, each performed in triplicate. Statistical significance was analyzed by the Mann-Whitney $\mathrm{U}$ test.

\section{Results}

3.1. Bioinformatic Selection for Secreted Proteins in Trypanosomatids. The preliminary analysis of the $19613 \mathrm{~T}$. cruzi putative proteins from the CL-Brener genome was performed to discard potential uncompleted sequences. A total of 1796 sequences were removed manually since they did not bear an initial methionine amino acid. The remaining 17817 (90.8\%) protein coding sequences were kept for subsequent analysis. House-keeping genes and sequences belonging to large gene families, like the trans-sialidases, mucins, Mucin-Associated Surface Proteins (MASPs), were discarded given that the main goal was to identify novel secreted proteins. Finally, sequences encoding proteins with a molecular weight above $90 \mathrm{kDa}$ were eliminated, in order to facilitate subsequent gene cloning. The remaining coding sequences were screened for the presence of both the signal peptide and the peptidase cleavage site with a probability of 0.8 and 0.7 , respectively. A total of 216 sequences were obtained by using these criteria. Among them, 91 (42\%) were annotated as "hypothetical proteins, conserved" in the data bank. The final criterion for selected proteins likely to be secreted by the classical eukaryotic pathway was the presence of the signal peptide and the signal peptidase site in orthologs of the related parasites: Leishmania major, $L$. infantum, and T. brucei. Among the 91 sequences, only 45 showed orthologs with the signal peptide criteria. The 13 proteins bearing the highest probability for the presence of the signal peptide were selected (Table 2) for confirmation of extracellular localization. Among the 13 selected genes, Tc00.1047053505789.10 and Tc00.1047053509835.30 are homologous genes and members of a multigene family (Table 2). These genes show about $40 \%$ identity at the protein level and possess the same predicted orthologs in the GeneDB server. Nevertheless in the TritrypDB resource the prediction of orthologs is different (see Table 2). This could be explained by the use of different algorithms (Jaccard cog clustering or OrthoMCL) for the prediction of orthologous groups [18]. The beta-tubulin T. cruzi gene (GeneID Tc00.1047053506563) was added to our sample as a potential negative control for protein secretion. Among the 13 selected genes, 7 genes were predicted to have transmembrane domains (Table 2). These genes were included for the functional test because previous studies identified extracellular proteins with putative transmembrane domains as constituents of the secretome of different pathogens, including $L$. donovani $[19,20]$. Furthermore, in the protozoa Toxoplasma gondii, the dense granule protein GRA5 is a transmembrane protein that bears a signal peptide and is secreted as a soluble protein into the vacuolar space, before being inserted into the parasitophorous vacuole membrane. Based on these studies, we included genes with potential transmembrane domains to test whether the presence of these domains represents a useful criterion for identifying extracellular secreted proteins.

\subsection{Transcription of the Selected Genes in the Different} Forms of T. cruzi Life Cycle. Reverse transcription-PCR (RTPCR) was performed for the 13 in silico selected genes in the different developmental stages of T. cruzi in order to verify transcription. The beta-tubulin T. cruzi gene (GeneID Tc00.1047053506563), constitutively expressed in all the three stages of T. cruzi, was used as a positive control for RNA quality. RT-PCR was positive for all genes in the infective trypomastigote and amastigote forms. Two genes (Gene ID Tc00.1047053511901.30 and Tc00.1047053509999.10) were negative for the amplification of cDNA in the noninfective epimastigote form (Figure 1) suggesting a possible stagespecific expression of these genes. Nevertheless, since trypanosomatid gene expression is almost exclusively regulated posttranscriptionally, further studies at the protein level have to confirm these observations.

\subsection{Experimental Approach for the Detection of Secreted} Proteins. A functional test was set up to confirm the presence of selected proteins in the extracellular environment by detection of target proteins in cell-free supernatants. The 13 selected encoding genes of T. cruzi and the gene encoding the beta-tubulin (negative control) were amplified from genomic 
TABLE 2: T. cruzi genes selected by in silico analysis and predicted properties of the encoded hypothetical proteins.

\begin{tabular}{|c|c|c|c|c|c|c|c|}
\hline \multirow{2}{*}{$\begin{array}{l}\text { T. cruzi GeneDB } \\
\text { Gene ID No. }\end{array}$} & \multirow{2}{*}{\multicolumn{2}{|c|}{$\begin{array}{l}\text { Orthologs } \\
\text { L. major and T. brucei Gene ID No. }{ }^{(a)}\end{array}$}} & \multicolumn{2}{|c|}{ Probability } & \multirow{3}{*}{$\begin{array}{c}\mathrm{TM}^{(\mathrm{d})} \\
1 \\
\end{array}$} & \multirow{3}{*}{$\begin{array}{c}\mathrm{GPI}^{(\mathrm{e})} \\
\text { Yes } \\
\end{array}$} & \multirow{3}{*}{$\begin{array}{l}\text { Conserved domains } \\
{\text { (and E-value) })^{(\mathrm{f})}}^{\text {None }}\end{array}$} \\
\hline & & & \multirow{2}{*}{$\begin{array}{r}\mathrm{SPP}^{(\mathrm{b})} \\
0.937\end{array}$} & \multirow{2}{*}{$\begin{array}{c}\operatorname{CSP}^{(\mathrm{c})} \\
0.917 \\
\end{array}$} & & & \\
\hline Tc00.1047053506417.30 & LmjF22.0225 & Tb927.8.2180* & & & & & \\
\hline Tc00.1047053506155.99 & LmjF36.5220 & Tb11.01.2470 & 0.984 & 0.962 & 0 & No & $\begin{array}{l}\text { Glucosidase II beta } \\
\text { subunit-like } \\
(\mathrm{E}=1.6 \mathrm{e}-13)\end{array}$ \\
\hline Tc00.1047053506467.29 & LmjF26.2000 & Tb09.160.1070 & 0.811 & 0.771 & 0 & Yes & $\begin{array}{l}\text { Methyltransferase } \\
\text { domain }(\mathrm{E}=4.3 \mathrm{e}-4)\end{array}$ \\
\hline Tc00.1047053511901.30 & LmjF24.2160 & Tb927.8.6080 & 0.989 & 0.898 & 0 & No & $\begin{array}{l}\text { Glycerophosphoryl } \\
\text { diester phosphodies- } \\
\text { terase }(\mathrm{E}=5.7 \mathrm{e}-8)\end{array}$ \\
\hline Tc00.1047053511871.30 & LmjF25.1010* & Tb927.3.950* & 0.979 & 0.958 & 0 & No & $\begin{array}{l}\text { 2OG-Fe(II) oxygenase } \\
(\mathrm{E}=1.7 \mathrm{e}-13) \\
\end{array}$ \\
\hline Tc00.1047053505789.10 (g) & LmjF19.0540* & Tb927.8.6700 (h) & 1.000 & 0.768 & 5 & No & $\begin{array}{l}\text { Lipocalin signature } \\
(\mathrm{E}=0.0)\end{array}$ \\
\hline Tc00.1047053509669.70 & $\begin{array}{l}\text { LmjF19.0570* } \\
\text { LmjF29.1600 }\end{array}$ & $\begin{array}{c}\text { Tb11.39.0005(i) } \\
\text { Tb927.3.4190 }\end{array}$ & 0.999 & 0.980 & 9 & No & $\begin{array}{l}\text { Endomembrane } \\
\text { protein } 70(\mathrm{E}=0.0)\end{array}$ \\
\hline Tc00.1047053507765.20 & LmjF11.0720 & Tb11.02.4400 & 0.993 & 0.986 & 0 & No & None \\
\hline Tc00.1047053510101.470 & LmjF11.0720 & Tb11.02.4400 & 0.931 & 0.919 & 0 & No & None \\
\hline Tc00.1047053510443.30 & LmjF30.3150 & Tb927.6.4500 & 0.903 & 0.838 & 1 & No & $\begin{array}{l}\text { Translocon-associated } \\
\text { protein beta (TRAPB) } \\
(\mathrm{E}=4.1 \mathrm{e}-4)\end{array}$ \\
\hline Tc00.1047053509799.50 & LmjF36.5570 & Tb10.6k15.1130 & 0.981 & 0.931 & 1 & No & None \\
\hline Tc00.1047053509835.30(g) & $\begin{array}{l}\text { LmjF19.0540* } \\
\text { LmjF19.0570* }\end{array}$ & $\begin{array}{l}\text { Tb927.8.6700 } \\
\text { Tb11.39.0005 } \\
\text { (i) }\end{array}$ & 0.866 & 0.803 & 5 & No & $\begin{array}{l}\text { Heavy-metal- } \\
\text { associated domain, } \\
\text { Heavy metaltrans- } \\
\text { port/detoxification } \\
(\mathrm{E}=0.0)\end{array}$ \\
\hline Tc00.1047053509999.10 & LmjF29.1200* & Tb927.3.3820 & 1.000 & 0.952 & 3 & No & None \\
\hline $\begin{array}{l}\text { (a) L. major and T. brucei gene I } \\
\text { * Nonsyntenic predicted orthol } \\
\text { (b) SPP Signal peptide probabili } \\
\text { (c) CSP Maximal cleavage site p } \\
\text { (d) TM Number of transmembr } \\
\text { (e) GPI Identification of GPI-an } \\
\text { (f) Conserved domains (and cor } \\
\text { (g) Tc00.1047053505789.10 and } \\
\text { multigene family including Tc0 } \\
\text { (h) Tb927.8.6700, Tb927.8.6710 } \\
\text { Tc00.1047053509441.10, Tc00. } \\
\text { (i) Tb11.39.0005 represents the }\end{array}$ & $\begin{array}{l}\text { No. of putative orth } \\
\text { gs in the TriTrypDB } \\
\text { predicted by Signall } \\
\text { bability predicted by } \\
\text { ne domains (other th } \\
\text { hor signal by GPI-SO } \\
\text { esponding E-value) fi } \\
\text { Tc00.1047053509835 } \\
.1047053505789 .20, \\
\text { Tb927.8.6720, and } \\
047053510063.30 \text {, an } \\
\text { redicted ortholog of ' }\end{array}$ & $\begin{array}{l}\text { lologs from GeneDB. } \\
\text { server. } \\
\text { P 3.0. } \\
\text { y SignalP 3.0. } \\
\text { han peptide signal seque } \\
\text { OM. } \\
\text { rom InterPro, PROSITE } \\
\text { f.30 are homologous ge } \\
\text { Tc00.1047053509441.10 } \\
\text { Tb927.8.6730 represen } \\
\text { d Tc00.1047053510065 } \\
\text { Tc00.1047053509835.30 }\end{array}$ & $\begin{array}{l}\text { e) predic } \\
\text { r Pfam. } \\
\text { s present } \\
\text { Ic00.104 } \\
\text { the para } \\
\text { in the T } \\
\text { nd Tc00. }\end{array}$ & $\begin{array}{l}\text { TMHN } \\
5 \% \text { iden } \\
10063.3 \\
\text { rthologs } \\
\text { pDB serv } \\
5350423\end{array}$ & $\begin{array}{l}0 . \\
\text { the pro } \\
0.10470 \\
\text { c00.104 }\end{array}$ & $\begin{array}{l}\text { evel. Tl } \\
065.10 \\
05789 .\end{array}$ & $\begin{array}{l}\text { genes are members of a } \\
\text { Tc00.1047053504235.9. } \\
\text { Tc00.1047053505789.20, }\end{array}$ \\
\hline
\end{tabular}

DNA. A sequence encoding a 6xHis-Tag was added at the C-terminal end of each encoded gene, to allow subsequent detection of the protein in total parasite protein extracts or in concentrated cell-free supernatants (CCFSs). Amplified PCR products were cloned into the pTEX shuttle vector widely used for expression in trypanosomatids [14]. Transformation and selection of T. cruzi is not as easy to perform as for Leishmania, mainly due to longer periods required for selecting drug-resistant parasites. Since we aimed to develop a fast and reliable approach to identify trypanosomatid conserved secreted proteins, we used the related Leishmania parasite as the recipient organism for the experimental validation of our selected proteins. Thus, L. infantum promastigotes were separately transformed with pTEX carrying one of the 14 selected $T$. cruzi genes (including the beta-tubulin gene), and the recombinant parasites were selected for resistance to Geneticin G418. Each parasite population was checked for the presence of both the $\mathrm{NEO}^{\mathrm{R}}$ gene and the selected gene whose secretion was to be analyzed. A specific 800 bp fragment, indicative of the presence of the $\mathrm{NEO}^{\mathrm{R}}$ gene, was detected in the transfected promastigotes and not in wild-type parasites (Figure 2(a)). Moreover, the presence of each candidate gene in recombinant parasites was confirmed using specific primers designed from $T$. cruzi gene sequences (Figure 2(b)). PCRs performed on wild type Leishmania were negative, demonstrating that the amplification was 


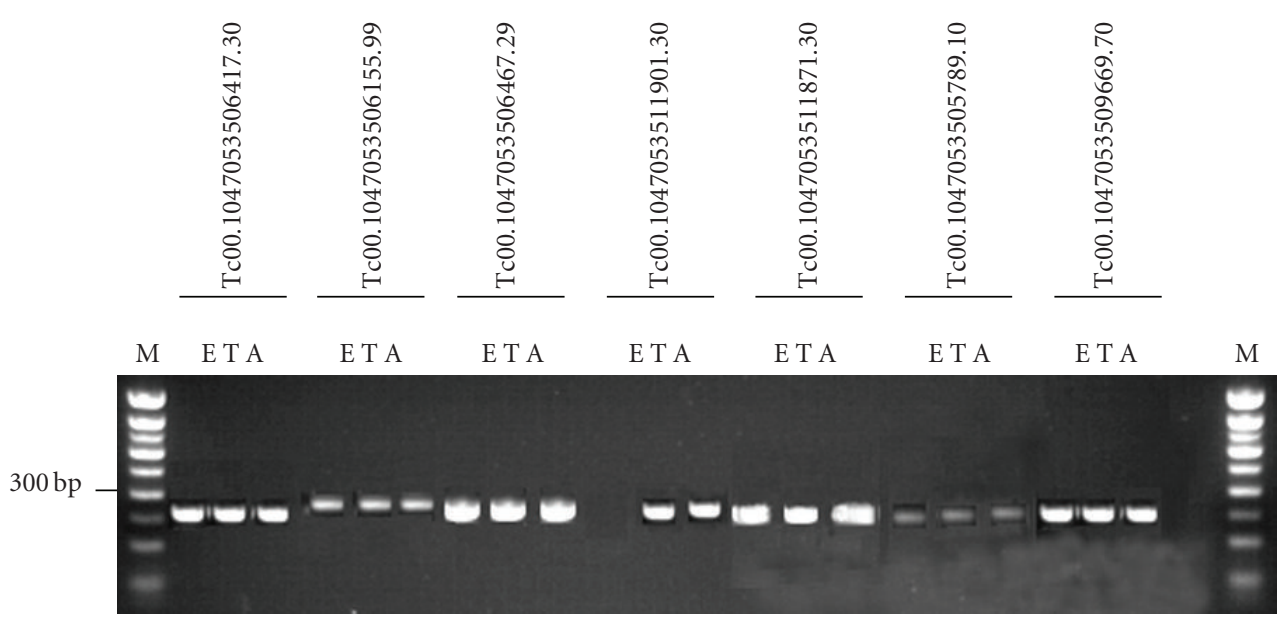

(a)

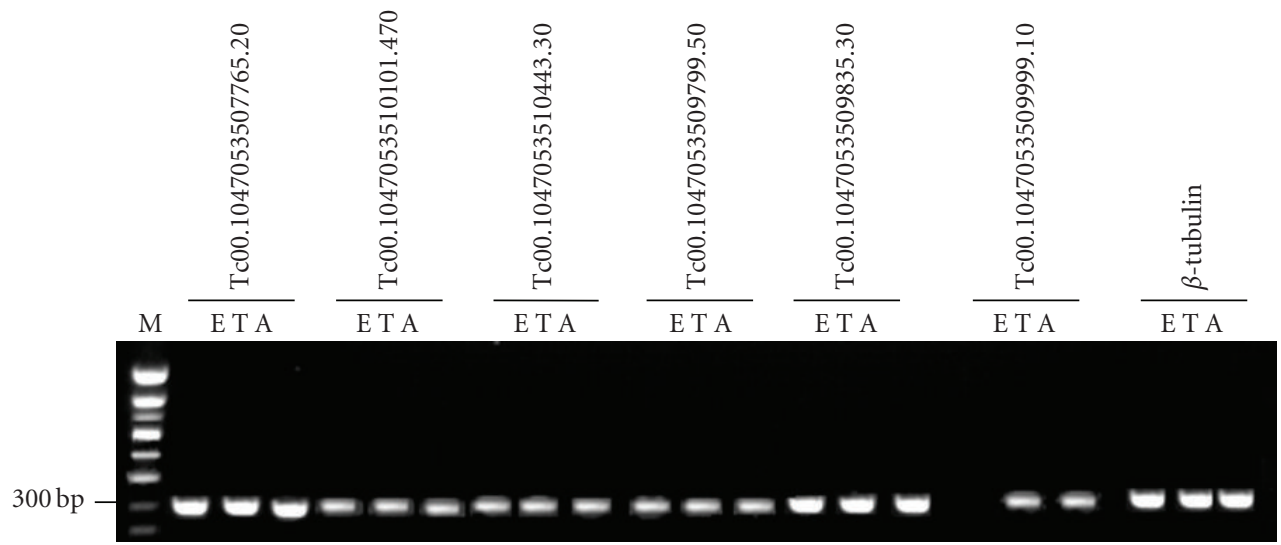

(b)

FIgURE 1: Amplification of the cDNAs encoding the potentially secreted proteins in the different stages of T. cruzi: RT-PCR analysis of total RNA from T. cruzi (clone derived from the Y strain) epimastigotes (E), trypomastigotes (T), and amastigotes (A). cDNA was amplified using gene-specific PCR primers (Listed in Table 1). Gene ID and expected lengths of cDNA are listed in order in Table 1. M: Molecular marker: Smart Ladder SF.

genus specific although the genes are conserved in both trypanosomatids (data not shown). The expression of these genes was screened using an antibody directed against the His-Tag carried by the recombinant proteins (Figure 3(a)). Western blot analysis demonstrated that (i) it was possible to easily and specifically detect the $6 \mathrm{xHis}$ tag protein in the extract derived from recombinant parasites, (ii) recombinant Leishmania expressed a relatively high level of $T$. cruzi protein, and (iii) the molecular weight of the detected tagged protein corresponded to the expected MW (see Table 1).

Subsequently, an approach was set up to detect recombinant proteins in cell-free supernatants. In order to limit potential contamination by proteins derived from dying organisms, incubation in serum-free mediums was restricted to 6 hours, and the viability of parasite populations was checked before and after this incubation period. Parasites and cell-free supernatants were collected if the viability of the cell population was above $98 \%$. Western Blot analysis of the concentrated cell-free supernatants revealed that among the 14 proteins, only 3 were actively secreted (Tc00.1047053506155.99, Tc00.1047053505789.10, and Tc00.1047053509999.10) (Figure 3(b)). These proteins represent genuine secreted material, since (i) the overexpression of the beta-tubulin gene does not induce translocation of the beta-tubulin protein into the extracellular space (difference between Lys and CCFS in Figure 3(b)), and (ii) the detection of the tagged protein in the cell-free supernatant is not related to the level of its expression by Leishmania (low abundance of Tc00.1047053506155.99 in Figure 3(b)). As expected, a slight molecular weight difference was observed between the tagged protein detected into the whole soluble extract and that detected in the cell-free supernatant that could be explained by the loss of the Signal Peptide (Figure 3(b)). As anticipated, no cross-reactive band was detected in wild-type parasites (Figure 3(b)). To confirm that the secretion observed was not related to the heterologous expression system, two Leishmania genes (Gene ID LinJ19.0410 and LinJ36.5780) corresponding to the orthologs of Tc00.1047053505789.10 and Tc00.1047053506155.99 genes were selected to validate 


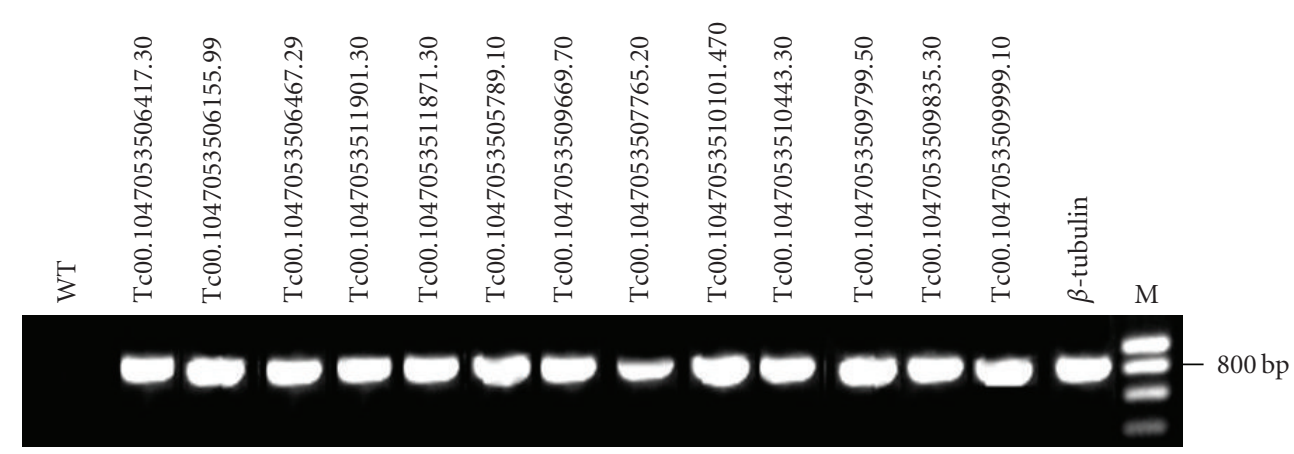

(a)

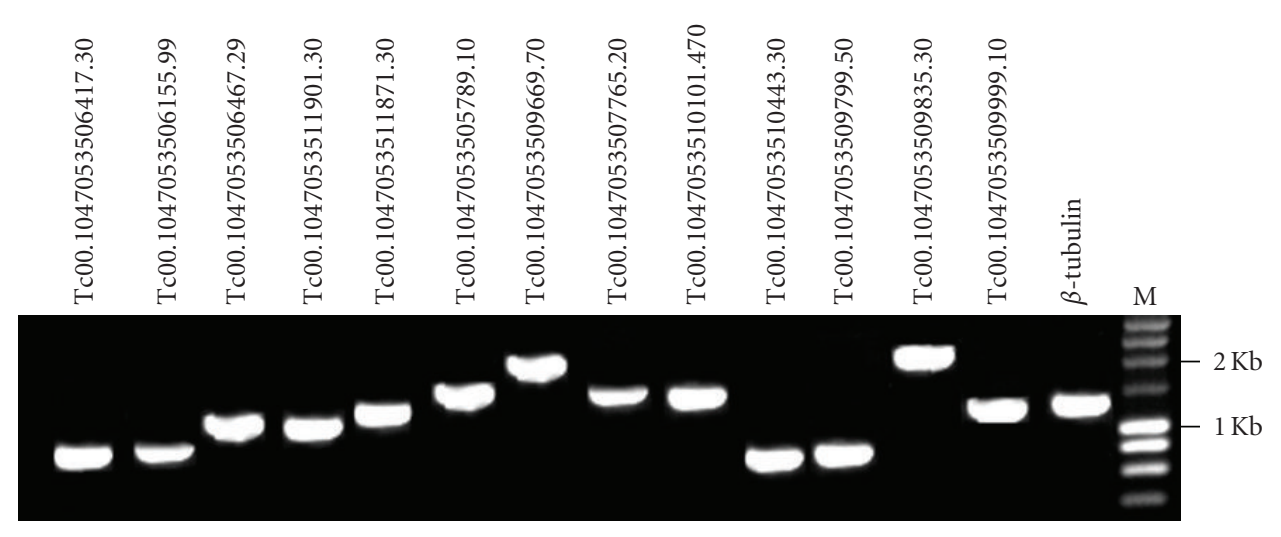

(b)

FIGURE 2: PCR analyses in episomally transfected L. infantum promastigotes. (a)Amplification of NEO gene fragment in L. infantum episomally transfected promastigotes. (b) Amplification of full length transfected genes in L. infantum promastigotes. Specific forward and Reverse PCR primers and gene lengths are listed in order in Table 1. WT: Wild Type Parasites. M: Molecular marker: Smart Ladder SL.

our approach. By using the same protocol as above, Leishmania expressing the $6 \mathrm{xHis}$ tagged proteins were generated (See Table 3). As expected, the presence of the tagged protein in the extracellular medium was only detected in the episomally transfected parasites (Figure 4). Together, these results indicate that this approach allows the identification of new and genuinely extracellular proteins involved in the endoplasmic reticulum/Golgi-dependent secretory pathway.

\subsection{Expression of Secreted Proteins Increases Ability of} Recombinant Leishmania Parasites to Infect and Survive inside Macrophages In Vitro. We attempted to determine whether the expression of Leishmania-secreted proteins could interfere with the capacity of recombinant parasites to replicate within human macrophages in vitro. Both confirmed secreted proteins (LinJ19.0410 and LinJ36.5780) from $L$. infantum were tested by using the luciferase reporter system in transfected parasites overexpressing these proteins. We used bioluminescence as a quantitative indicator of the viability and multiplication of parasites. The number of promastigotes cells and luciferase activity were linearly correlated for the different recombinant parasites before macrophage infection (data not shown). Results of in vitro infection showed that overexpression of secreted protein LinJ19.0410 (ortholog of Tc00.1047053505789.10) increases the capacity of Leishmania to survive in THP-1 differentiated macrophages as early as 24 hours postinfection (Figure 5). Furthermore, a statistically significant increase in luciferase activity of recombinant parasites expressing LinJ19.0410 was maintained throughout the experiments $(P<.05)$. This effect was not observed in parasites overexpressing LinJ36.5780 (ortholog of Tc00.1047053506155.99) where infectivity levels were similar to the control parasites transfected with the pTEX vector alone and the pSP- $\alpha \mathrm{HYG} \alpha \mathrm{LUC}$ (Figure 5).

\section{Discussion}

In trypanosomatids the secretion process is not fully understood and various pathways including classical and nonclassical mechanisms may contribute to the formation of the "extracellular proteome." Thus the individual identification of secreted materials would enhance efforts towards understanding mechanisms of protein secretion in these medically important parasites. In an attempt to provide a new approach to analyse the large number of hypothetical conserved proteins in trypanosomatids, we developed an experimental approach to identify hypothetical extracellular proteins likely to be involved in the classical pathway. We combined a web-based bioinformatics approach that used the Signal P 3.0 program, one of the most accurate predictors for the presence of a signal peptide sequence [21], with 


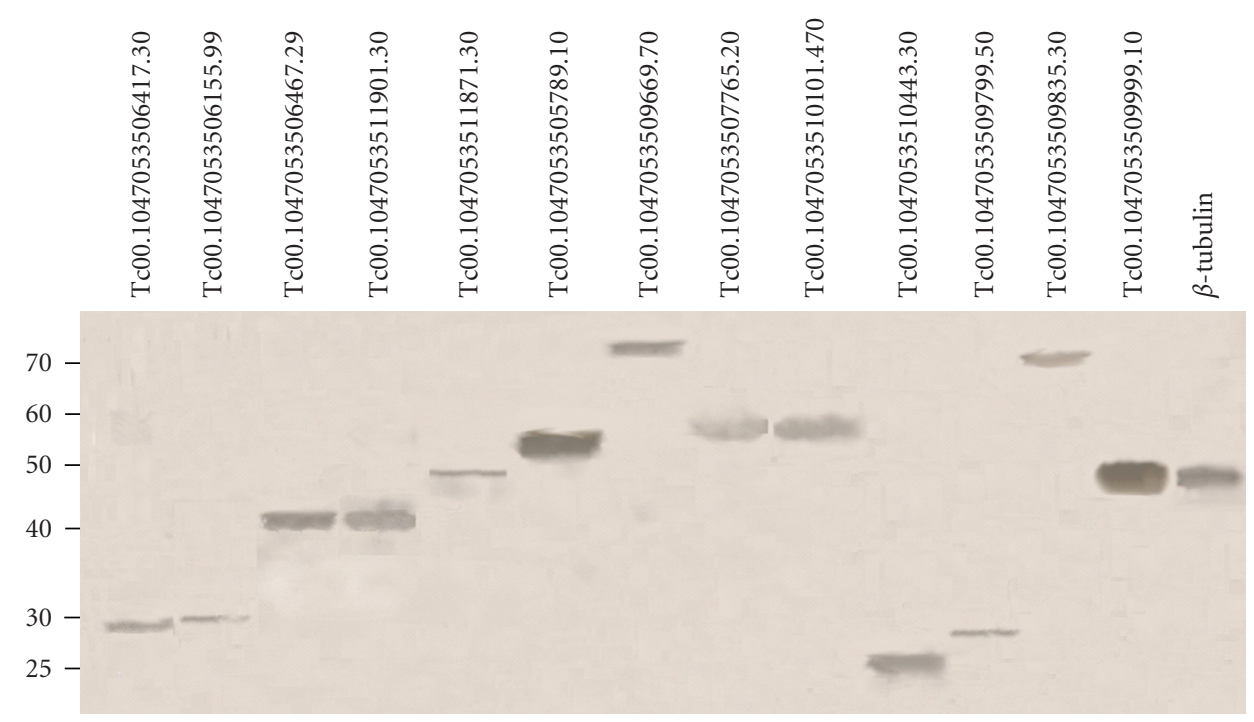

(a)

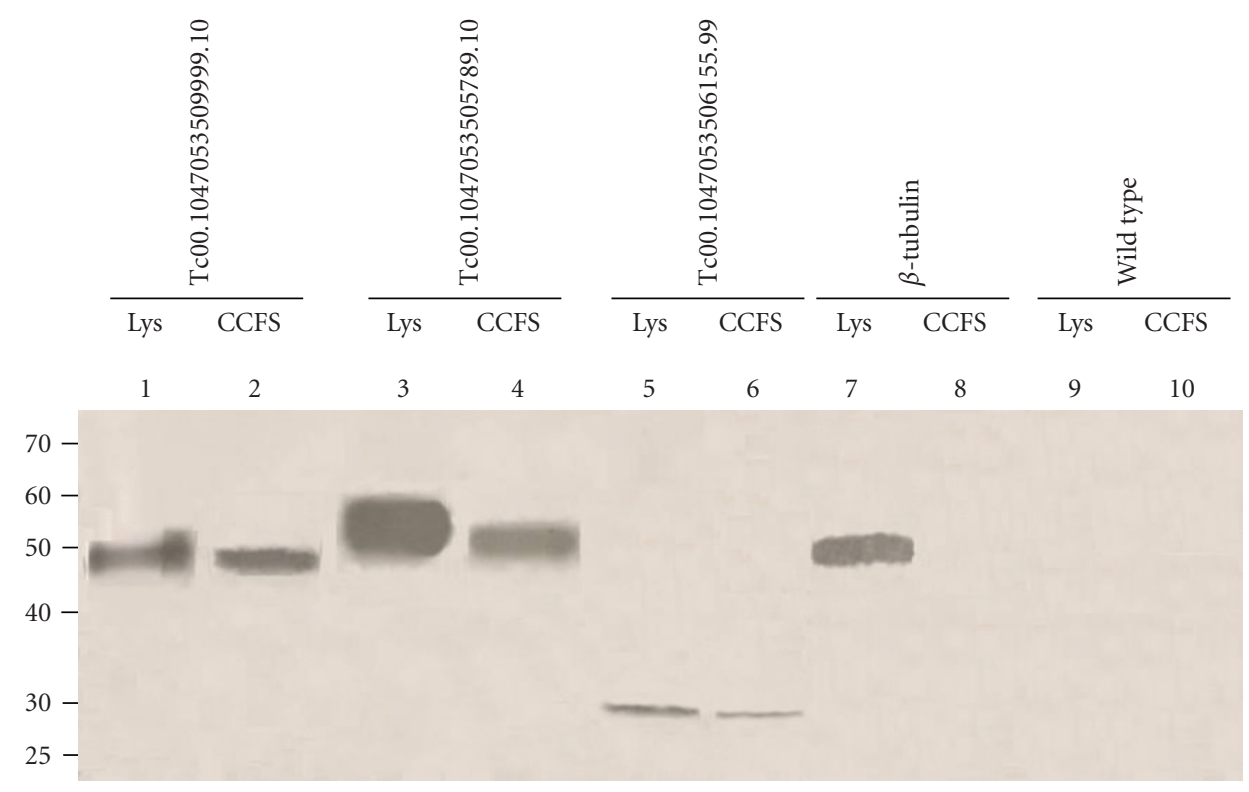

(b)

FIGURE 3: Protein expression in L. infantum episomally transfected promastigotes during the exponential phase of development (a) Western blot analysis of His-tagged proteins detected in whole cell lysate. Equal amounts of total protein $(35 \mu \mathrm{g})$ were resolved by electrophoresis in $4-12 \%$ gradient gels (Invitrogen), blotted, and developed with anti-HisTag antibody followed by ECL (Amersham). Gene ID and the theoretical molecular weight of detected proteins are listed in order in Table 1. (b) Identification of secreted proteins in whole cell lysate (Lys) and concentrated cell-free culture supernatant (CCFS) obtained from promastigotes incubated for 6 hours in serum-free medium. Note the absence of $\beta$ Tubulin in the concentrated supernatant of Line 8. Nontransfected $L$. infantum promastigotes (Wild Type) were used as a negative control. Protein molecular mass standards in $\mathrm{kDa}$ are shown on the left of each panel.

a functional test that takes advantage of the relative ease to genetically transform Leishmania. We assumed that a phylogenetic conservation among Leishmania, T. cruzi, and T. brucei would point to evolutionary selection for this family of proteins and indicate an important role for these proteins in the biology of these parasites. Using these criteria we selected a pool of 13 trypanosomatid-conserved hypothetical proteins from the T. cruzi database for which secretion was tested.
Identification of secreted proteins has been hampered in trypanosomatids due to the difficulty in distinguishing genuine secretions from molecules released by lysed, dead, or dying organisms. Additionally, the in vitro growth of trypanosomatid developmental stages that occur in mammals is impossible or laborious.

Characterization by screening cDNA libraries with sera raised against culture medium supernatants has been performed for the identification of extracellular proteins 
TABLE 3: Gene ID of L. infantum orthologous genes and primers used for cloning.

\begin{tabular}{llll}
\hline Gene ID & Primer sequences $^{(\mathrm{a})}$ & F/R product sizes $(\mathrm{bp})$ & $\mathrm{MW}(\mathrm{kDa})^{(\mathrm{b})}$ \\
\hline \multirow{2}{*}{ LinJ19.0410 } & (c) & F CATGACCACTAGTATGGCCAAAACAGCGCTTCTC & 1590 \\
& R GCAGTCCAAGCTTTTAGTGATGGTGATGATGATG & & \\
& AGGTGTTCTCAGGGGTGACGA & \\
\hline \multirow{2}{*}{ LinJ36.5780(d) } & F CATGCTCGACTAGTATGGGGTGCCGCAGTAGCTG & \\
& R GCAGTCCAAGCTTTTAATGATGATGGTGGTGATG & 738 & 28 \\
& ATCATCCAACATCTGGCACCGC & & \\
\hline
\end{tabular}

F: Forward primer including the start codon; R: Reverse primer used for the amplification of the full-length ORF.

(a) Restriction sites used for cloning in the pTEX vector in italics and the His-Tag sequence in bold.

(b) Expected molecular weight of the proteins.

(c) Ortholog of LmjF19.0540 and Tc00.1047053505789.10.

(d) Ortholog of LmjF36.5220 and Tc00.1047053506155.99.

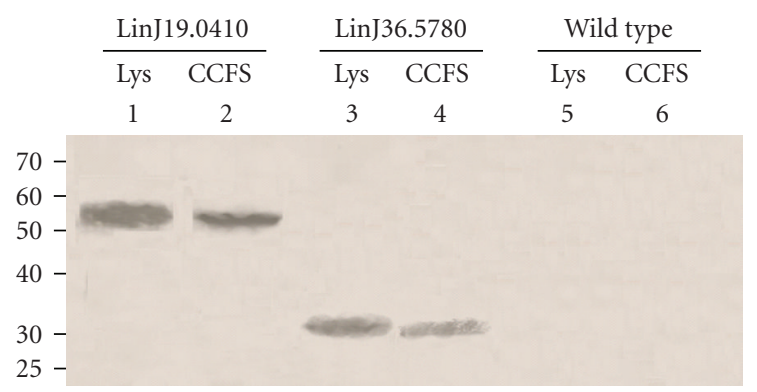

Figure 4: Homologous expression of secreted proteins in L. infantum episomally transfected promastigotes. L. infantum promastigotes were transfected with genes LinJ19.0410 and LinJ36.5780 corresponding to secreted proteins Tc00.1047053505789.10 and Tc00.1047053506155.99, respectively. Cell whole lysate (Lys) and concentrated cell-free culture supernatant (CCFS) and electrophoresis procedure were as in Figure 3. Tagged proteins were detected only in recombinant parasites transfected with LinJ19.0410 (58 kDa) (Line 1 and 2) and LinJ36.5780 (28 kDa) (Line 3 and 4). Nontransfected L. infantum promastigotes (Wild Type) were used as negative controls (Line 5 and 6). Protein molecular mass standards in $\mathrm{kDa}$ are shown on the left.

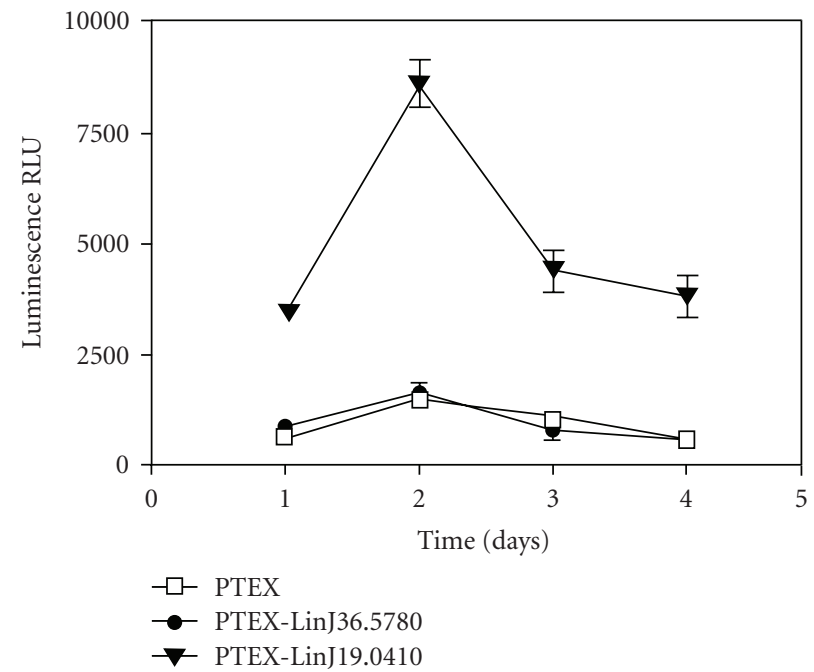

FIGURE 5: Bioluminescence activity of intracellular Leishmania expressing episomal luciferase from infected macrophages in vitro. Recombinant L. infantum promastigotes overexpressing the secreted proteins pTEX-LinJ19.0410 ( $\mathbf{\nabla})$ or pTEX-LinJ36.5780 $(\bullet)$ were cotransfected with the pSP-Y $\alpha \mathrm{HYGRO} \alpha \mathrm{LUC}$ carrying the firefly-luciferase gene. Survival of luciferase-expressing parasites was monitored in infected human monocyte cell line THP-1 differentiated into macrophages as indicated in the Methods section. Promastigotes transfected with the pTEX vector alone and the pSP- $\alpha \mathrm{HYG} \alpha \mathrm{LUC}(\square)$ were used as control for infection experiments. RLUs (Relative Luminescence Units) were measured at various time points post infection using the Steady Glo reagent. Results are expressed as the mean of three independent experiments, each carried out in triplicate. 
$[22,23]$. However, using this approach proteins with a low abundance or that are poorly immunogenic are likely to be missed. A more exhaustive approach relying on a highly sensitive methodology, like the quantitative mass spectrometry, was recently used to analyze the protein content of the whole conditioned medium from stationaryphase L. donovani promastigotes [19]. Nevertheless, proteins produced at low abundance and that are mainly exported to the extracellular compartment are likely to be missed, since the method relies on the comparison of conditioned medium versus cell-associated proteins. Indeed proteins that are well known to be extracellular, such as chitinase and SAcP (secreted acid phosphatase), were not identified with the SILAC-based approach [19]. The method we designed allowed us to identify three new trypanosomatid conserved proteins, likely to be secreted through the classical secretory pathway. We were confident that the proteins detected in the cell-free supernatant were genuinely secreted since (i) we were not able to detect the beta-tubulin-tagged protein in the cell-free supernatant after overexpression of the gene, (ii) the 6-hour incubation time avoided excessive cell death and contamination by proteins released from dead parasites, (iii) in the extracellular environment we detected orthologous Leishmania proteins (LinJ19.0410, LinJ36.5780) suggesting that secretion in this protein family is likely to be evolutionary conserved, and (iv) we detected no relation between the amount of secreted protein and its intracellular expression in the transfected parasites, demonstrating that the translocation of the his-tagged protein into the cell supernatant is not related to the methodology we used.

A recent study involving conditioned medium derived from stationary-phase Leishmania promastigotes [19] demonstrated that the extracellular proteome was mainly composed of proteins derived from different microvesicles. The parasite growth phase studied by these authors contains the infectious metacyclic parasites and also a high percentage of dying parasites in apoptosis [24]. Consequently, the analysis of extracellular material revealed that the main contributors to the "extracellular proteome" are vesicles likely to be "apoptotic vesicles" or "blebs" [25]. This work leads to the general conclusion that $98 \%$ of the proteins of the Leishmania secretome lacked a targeting signal, indicating that nonclassical secretion pathways are likely to be the dominant way by which Leishmania export proteins [19]. The proteomic characterization of the released/secreted proteins of $L$. braziliensis promastigotes showed that about $5 \%$ of the identified proteins possess a putative N-Signal peptide [26], indicating that protein export may depend on unconventional pathways as suggested in L. donovani. However, some evidence strongly supports the notion that the classical secretory pathway is operational in trypanosomatids and contributes to the composition of the parasite's secretome. For example, the screening of an L. major cDNA library with antiserum raised against culture supernatant from stationary-phase promastigotes led to the detection of 8 proteins bearing a potential signal peptide among the 33 genes identified [23]. Moreover some of the well-known Leishmania proteins found in the extracellular environment have a signal peptide for secretion, such as gp63 or chitinase [3, 27]. In the current work we deliberately decided to experimentally validate the secretion of our candidate proteins during the exponential growth phase of Leishmania in order to avoid contamination of the cell-free supernatant by apoptotic vesicles or exosomes. In these conditions we did not detect the secretion of tubulin, even in an overexpression model of Leishmania transfectants, while tubulin was identified with a significant score in the Leishmania secretome studied by the proteomic analysis performed during the stationary-phase [19]. Therefore, our results suggest that tubulin might be associated with exosomes and/or apoptotic vesicles generated by promastigotes in the stationary-phase of growth. We suggest that the composition of the parasite "extracellular proteome" is variable and depends both on the parasite stage under consideration and on the relative contribution of the various pathways operating in protein secretion. Further studies are required to highlight the importance of both classical and nonclassical secretory pathways in different developmental stages of trypanosomatids. Since we selected and tested secretion for several genes in the trypanosomatid genomes, our methodology provides a potential tool for genomewide screening to identify extracellular proteins. Furthermore, our methodology may complement other strategies, such as the SILAC approach, for the identification of proteins missed when using proteomic-based approaches.

Regarding proteins not detected in the extracellular environment, it is important to point out that proteins bearing a signal peptide are not only targets for secretion but also for transfer to specific organelles, for example, lysosomes or the cell surface. Thus, these proteins could be retained in specific organelles within the parasite or attach to the cell surface via a GPI-anchor. In this light, analysis of the 13 proteins with GPI-SOM [28] suggests that 2 out of 13 proteins ( $\mathrm{Tc} 00.1047053506417 .30$ and Tc00.1047053506467.29) have a predicted glycosyl-inositol phosphate (GPI) anchor signature sequences. Hence, the presence of the GPI anchored domain may explain the absence of these proteins in the culture supernatant of recombinant parasites.

An unexpected finding in our results was the prediction of transmembrane helices in two of our secreted proteins (Tc00.1047053505789.10 and Tc00.1047053509999.10). We included proteins with transmembrane domains to test whether their presence in protein sequences is a suitable criterion for the prediction of extracellular secreted proteins. Previous studies suggested that the presence of transmembrane helices in protein sequences is not a suitable criterion for discarding potentially secreted proteins $[19,20]$. In this regard our results provide further evidence that empirical studies are required to verify bioinformatic predictions since two of the extracellular proteins bear transmemebrane domains. However, another speculative explanation for the presence of transmembrane domains is the potential insertion of secreted materials into membranes after secretion, as demonstrated for the pathogen Toxoplasma gondii $[29,30]$. 
The secreted protein Tc00.1047053505789.10 contains a lipocalin signature. Lipocalins are a widely distributed group of mostly extracellular proteins, several of which have been implicated in the regulation of host immune responses, such as, alpha-1-microglobulin and alpha-1-acid glycoprotein [31]. Despite a well-conserved tertiary structure of lipocalins, the pairwise sequence identity within this family is low, often below 30\%, [32]. This may explain the absence of a predicted lipocalin signature in the Leishmania spp. or T. brucei orthologs. Remarkably, the protein encoded by Tc00.1047053509835.30 (homolog of Tc00.1047053505789.10) lacks a lipocalin signature. Furthermore, this protein was not detected as extracellular in our experimental conditions. Although these genes belong to a multigene family (see Table 2) and possess about $40 \%$ identity at the protein level, our findings suggest a different cellular localization and/or function for the corresponding proteins. A clear assignment of the protein Tc00.1047053505789.10 to the lipocalin family would only be possible after NMR or X-ray crystallography structure analysis. Further studies are needed to ascertain if this large and diverse group of proteins is present in trypanosomatids and plays a role in the transmission process. A Glucosidase II beta subunit-like protein domain has also been detected in the protein Tc00.1047053506155.99. Although mostly localized to the ER, Glucosidase II was found in endocytic structures beneath the plasma membrane and has been associated with the protein-tyrosine phosphatase CD45 [33]. There is also evidence that in some cell types Glucosidase II beta is capable of being trafficked to the cell surface [34].

Having demonstrated that our methodology is reliable for the identification of extracellular secreted proteins in trypanosomatids, we tested the hypothesis that recombinant Leishmania parasites carrying extra copies of Leishmania secreted proteins may interfere with their survival or infectivity towards human monocyte-derived macrophages in vitro. Results of these assays showed a significant survival advantage to Leishmania parasites overexpressing the gene LinJ19.0410 (Ortholog of Tc00.1047053505789.10) suggesting that this protein is involved in a process increasing survival and/or replication of the parasite inside its target cell. Given that Leishmania and T. cruzi do not target the same host cells and follow different cell invasion processes, further experiments in the T. cruzi homologous system are needed to address whether the identified secreted protein Tc00.1047053505789.10 from T. cruzi is also involved in host cell invasion and/or replication. Current in vitro and in vivo studies are in progress to characterize this protein which represents a potential conserved virulence factor in trypanosomatids.

\section{Conclusions}

In conclusion, our results show that the bioinformatics method combined with the functional tests, provides a fast and reliable method for the identification of novel extracellular secreted proteins involved in the classical secretory pathway and represents potential virulence factors in trypanosomatids.

\section{Acknowledgments}

Financial support for this study was provided by the European Union through a Grant to R. M. Corrales by the "Programme Alßan" European Union Programme of High Level Scholarships for Latin America (no. E05D057391AR) and by IRD DSF. The authors thank B. Vergnes for critical review of the manuscript and P. Agnew for help revising the manuscript's English.

\section{References}

[1] K. Stuart, R. Brun, S. Croft, et al., "Kinetoplastids: related protozoan pathogens, different diseases," The Journal of Clinical Investigation, vol. 118, no. 4, pp. 1301-1310, 2008.

[2] N. Santarem, R. Silvestre, J. Tavares, et al., "Immune response regulation by Leishmania secreted and nonsecreted antigens," Journal of Biomedicine and Biotechnology, vol. 2007, Article ID 85154, 6 pages, 2007.

[3] B. S. McGwire, W. A. O'Connell, K.-P. Chang, and D. M. Engman, "Extracellular release of the glycosylphosphatidylinositol (GPI)-linked Leishmania surface metalloprotease, gp63, is independent of GPI phospholipolysis. Implications for parasite virulence," The Journal of Biological Chemistry, vol. 277, no. 11, pp. 8802-8809, 2002.

[4] B. A. Burleigh and A. M. Woolsey, "Cell signalling and Trypanosoma cruzi invasion," Cellular Microbiology, vol. 4, no. 11, pp. 701-711, 2002.

[5] M. J. McConville, K. A. Mullin, S. C. Ilgoutz, and R. D. Teasdale, "Secretory pathway of trypanosomatid parasites," Microbiology and Molecular Biology Reviews, vol. 66, no. 1, pp. 122-154, 2002.

[6] J.-L. Lemesre, P. Holzmuller, R. B. Goncalves, et al., "Longlasting protection against canine visceral leishmaniasis using the $L i$ ESAp-MDP vaccine in endemic areas of France: doubleblind randomised efficacy field trial," Vaccine, vol. 25, no. 21, pp. 4223-4234, 2007.

[7] W. K. Tonui, J. S. Mejia, L. Hochberg, et al., "Immunization with Leishmania major exogenous antigens protects susceptible BALB/c mice against challenge infection with L. major," Infection and Immunity, vol. 72, no. 10, pp. 5654-5661, 2004.

[8] M. A. Horwitz, G. Harth, B. J. Dillon, and S. Maslesa-Galic, "Enhancing the protective efficacy of Mycobacterium bovis BCG vaccination against tuberculosis by boosting with the Mycobacterium tuberculosis major secretory protein," Infection and Immunity, vol. 73, no. 8, pp. 4676-4683, 2005.

[9] O. Emanuelsson, S. Brunak, G. von Heijne, and H. Nielsen, "Locating proteins in the cell using TargetP, SignalP and related tools," Nature Protocols, vol. 2, no. 4, pp. 953-971, 2007.

[10] E. Garzon, M. C. Borges, A. Cordeiro-da-Silva, et al., "Trypanosoma cruzi carrying a targeted deletion of a Tc52 proteinencoding allele elicits attenuated Chagas' disease in mice," Immunology Letters, vol. 89, no. 1, pp. 67-80, 2003.

[11] E. P. Camargo, "Growth and differentiation in Trypanosoma cruzi. I. Origin of metacyclic trypanosomes in liquid media," Revista do Instituto de Medicina Tropical de São Paulo, vol. 12, pp. 93-100, 1964.

[12] F. Mathieu-Daude, M.-F. Bosseno, E. Garzon, et al., "Sequence diversity and differential expression of Tc52 immunoregulatory protein in Trypanosoma cruzi: potential implications in the biological variability of strains," Parasitology Research, vol. 101, no. 5, pp. 1355-1363, 2007. 
[13] R. Brun and M. Schonenberger, "Cultivation and in vitro cloning of procyclic culture forms of Trypanosoma brucei in a semi-defined medium. Short communication," Acta Tropica, vol. 36, no. 3, pp. 289-292, 1979.

[14] J. M. Kelly, H. M. Ward, M. A. Miles, and G. Kendall, "A shuttle vector which facilitates the expression of transfected genes in Trypanosoma cruzi and Leishmania," Nucleic Acids Research, vol. 20, no. 15, pp. 3963-3969, 1992.

[15] D. Sereno, G. Roy, J. Loup Lemesre, B. Papadopoulou, and M. Ouellette, "DNA transformation of Leishmania infantum axenic amastigotes and their use in drug screening," Antimicrobial Agents and Chemotherapy, vol. 45, no. 4, pp. 1168$1173,2001$.

[16] B. Vergnes, D. Sereno, N. Madjidian-Sereno, J.-L. Lemesre, and A. Ouaissi, "Cytoplasmic SIR2 homologue overexpression promotes survival of Leishmania parasites by preventing programmed cell death," Gene, vol. 296, no. 1-2, pp. 139-150, 2002.

[17] A. El Fadili, C. Kundig, and M. Ouellette, "Characterization of the folylpolyglutamate synthetase gene and polyglutamylation of folates in the protozoan parasite Leishmania," Molecular and Biochemical Parasitology, vol. 124, no. 1-2, pp. 63-71, 2002.

[18] A. Kuzniar, R. C. H. J. van Ham, S. Pongor, and J. A. M. Leunissen, "The quest for orthologs: finding the corresponding gene across genomes," Trends in Genetics, vol. 24, no. 11, pp. 539-551, 2008.

[19] J. M. Silverman, S. K. Chan, D. P. Robinson, et al., "Proteomic analysis of the secretome of Leishmania donovani," Genome Biology, vol. 9, no. 2, article R35, 2008.

[20] A. Walz, C. V. Mujer, J. P. Connolly, et al., "Bacillus anthracis secretome time course under host-simulated conditions and identification of immunogenic proteins," Proteome Science, vol. 5, article 11, 2007.

[21] E. W. Klee and L. B. M. Ellis, "Evaluating eukaryotic secreted protein prediction," BMC Bioinformatics, vol. 6, article 256, 2005.

[22] P. Cibrelus, E. Precigout, D. Sereno, B. Carcy, J. L. Lemesre, and A. Gorenflot, "Secreted antigens of the amastigote and promastigote forms of Leishmania infantum inducing a humoral response in humans and dogs," Parasite, vol. 6, no. 2, pp. 121-129, 1999.

[23] M. Chenik, S. Lakhal, N. Ben Khalef, L. Zribi, H. Louzir, and K. Dellagi, "Approaches for the identification of potential excreted/secreted proteins of Leishmania major parasites," Parasitology, vol. 132, no. 4, pp. 493-509, 2006.

[24] H. Zangger, J. C. Mottram, and N. Fasel, "Cell death in Leishmania induced by stress and differentiation: programmed cell death or necrosis?” Cell Death \& Differentiation, vol. 9, no. 10, pp. 1126-1139, 2002.

[25] C. Thery, M. Boussac, P. Veron, et al., "Proteomic analysis of dendritic cell-derived exosomes: a secreted subcellular compartment distinct from apoptotic vesicles," The Journal of Immunology, vol. 166, no. 12, pp. 7309-7318, 2001.

[26] P. Cuervo, J. B. De Jesus, L. Saboia-Vahia, L. Mendonça-Lima, G. B. Domont, and E. Cupolillo, "Proteomic characterization of the released/secreted proteins of Leishmania (Viannia) braziliensis promastigotes," Journal of Proteomics, vol. 73, no. 1, pp. 79-92, 2009.

[27] M. B. Joshi, M. E. Rogers, A. M. Shakarian, et al., "Molecular characterization, expression, and in vivo analysis of LmexCht1: the chitinase of the human pathogen, Leishmania mexicana," The Journal of Biological Chemistry, vol. 280, no. 5, pp. 38473861, 2005.
[28] N. Fankhauser and P. Maser, "Identification of GPI anchor attachment signals by a Kohonen self-organizing map," Bioinformatics, vol. 21, no. 9, pp. 1846-1852, 2005.

[29] L. Lecordier, C. Mercier, L. D. Sibley, and M.-F. CesbronDelauwz, "Transmembrane insertion of the Toxoplasma gondii GRA5 protein occurs after soluble secretion into the host cell," Molecular Biology of the Cell, vol. 10, no. 4, pp. 1277-1287, 1999.

[30] V. Karsten, R. S. Hegde, A. P. Sinai, M. Yang, and K. A. Joiner, "Transmembrane domain modulates sorting of membrane proteins in Toxoplasma gondii," The Journal of Biological Chemistry, vol. 279, no. 25, pp. 26052-26057, 2004.

[31] J. Grzyb, D. Latowski, and K. Strzalka, "Lipocalins-a family portrait," Journal of Plant Physiology, vol. 163, no. 9, pp. 895915, 2006.

[32] D. R. Flower, A. C. T. North, and C. E. Sansom, "The lipocalin protein family: structural and sequence overview," Biochimica et Biophysica Acta, vol. 1482, no. 1-2, pp. 9-24, 2000.

[33] T. A. Baldwin, M. Gogela-Spehar, and H. L. Ostergaard, "Specific isoforms of the resident endoplasmic reticulum protein glucosidase II associate with the CD45 proteintyrosine phosphatase via a lectin-like interaction," The Journal of Biological Chemistry, vol. 275, no. 41, pp. 32071-32076, 2000.

[34] Y. M. Li, T. Mitsuhashi, D. Wojciechowicz, et al., "Molecular identity and cellular distribution of advanced glycation endproduct receptors: relationship of p60 to OST-48 and p90 to $80 \mathrm{~K}-\mathrm{H}$ membrane proteins," Proceedings of the National Academy of Sciences of the United States of America, vol. 93, no. 20, pp. 11047-11052, 1996. 

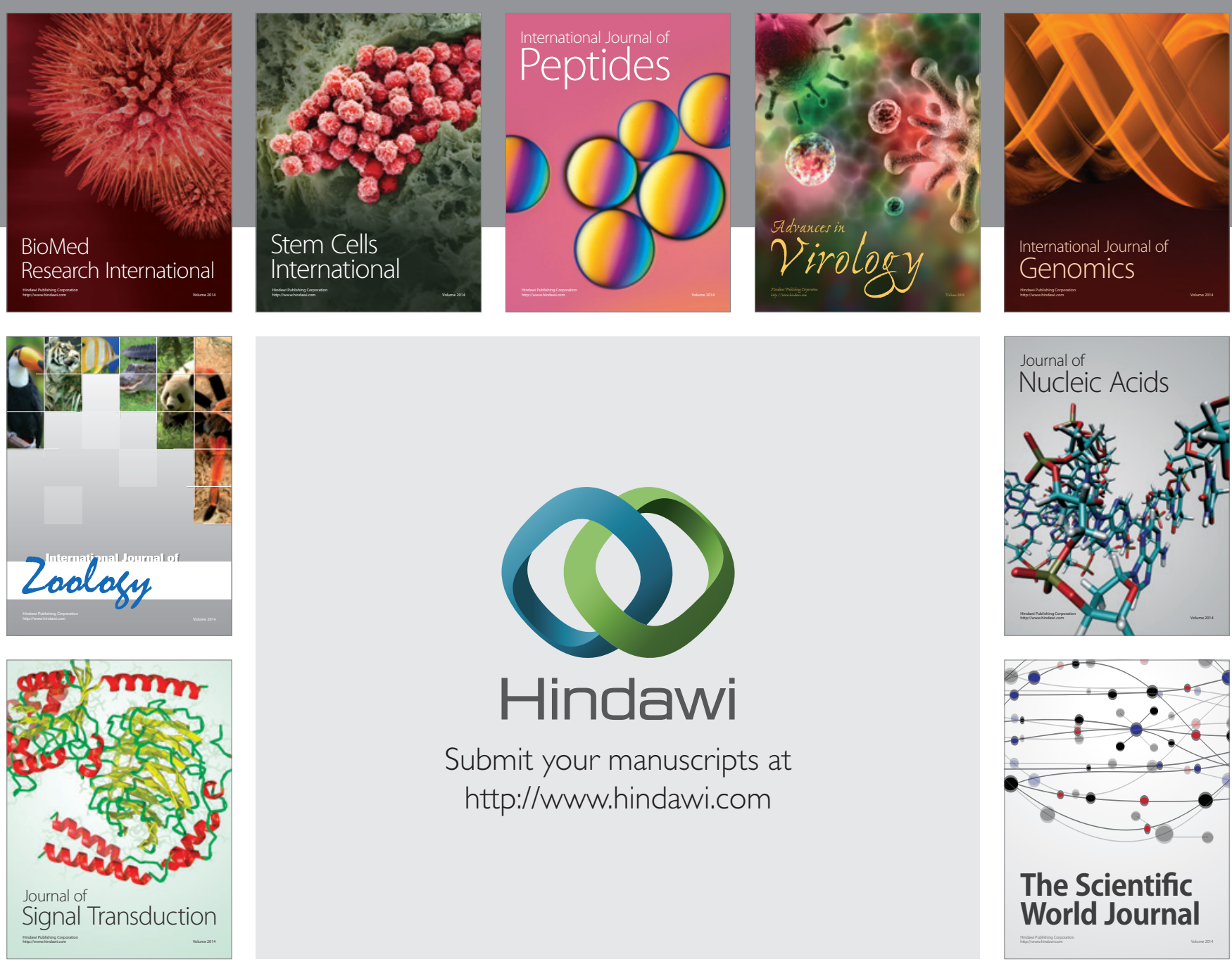

Submit your manuscripts at

http://www.hindawi.com
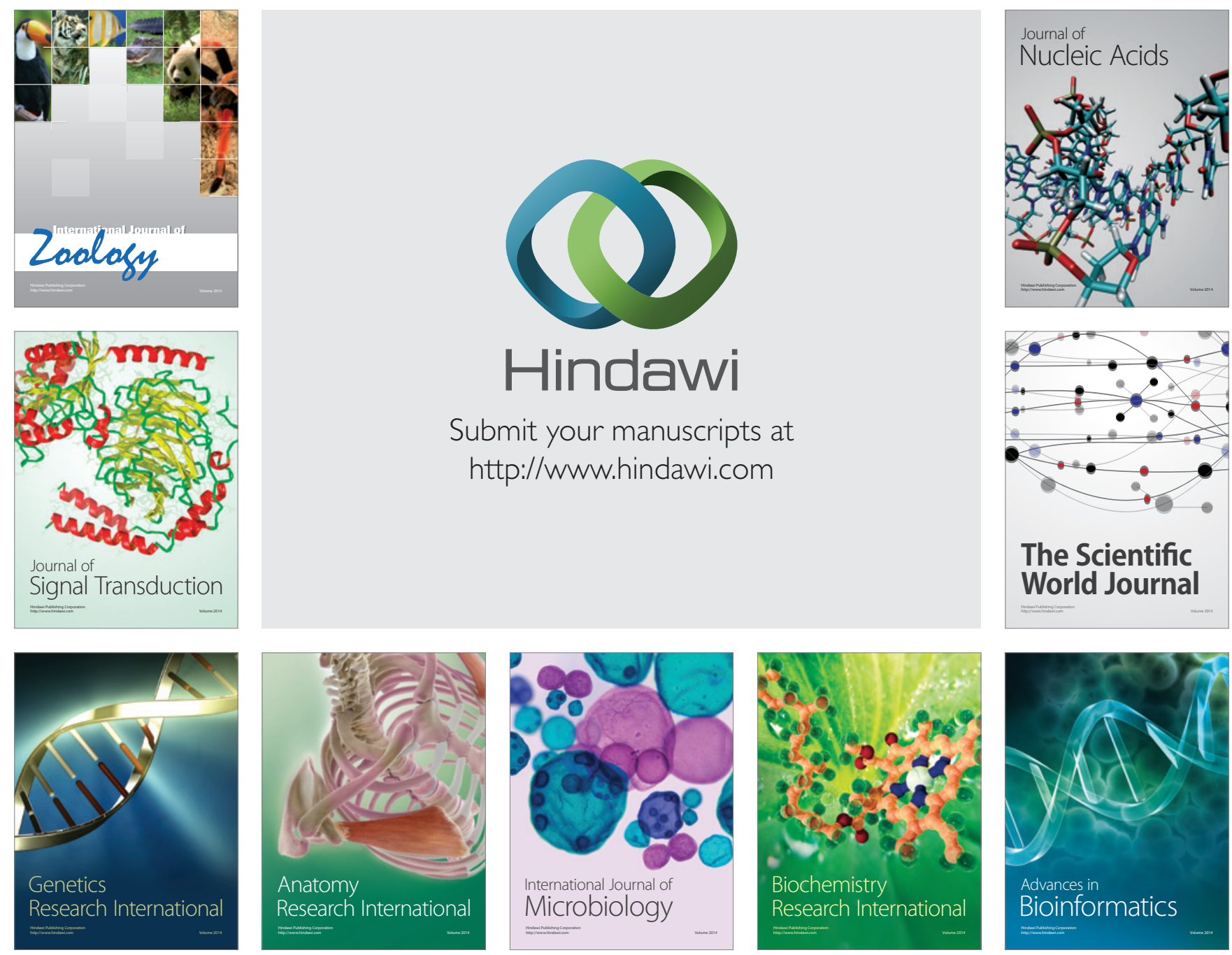

The Scientific World Journal
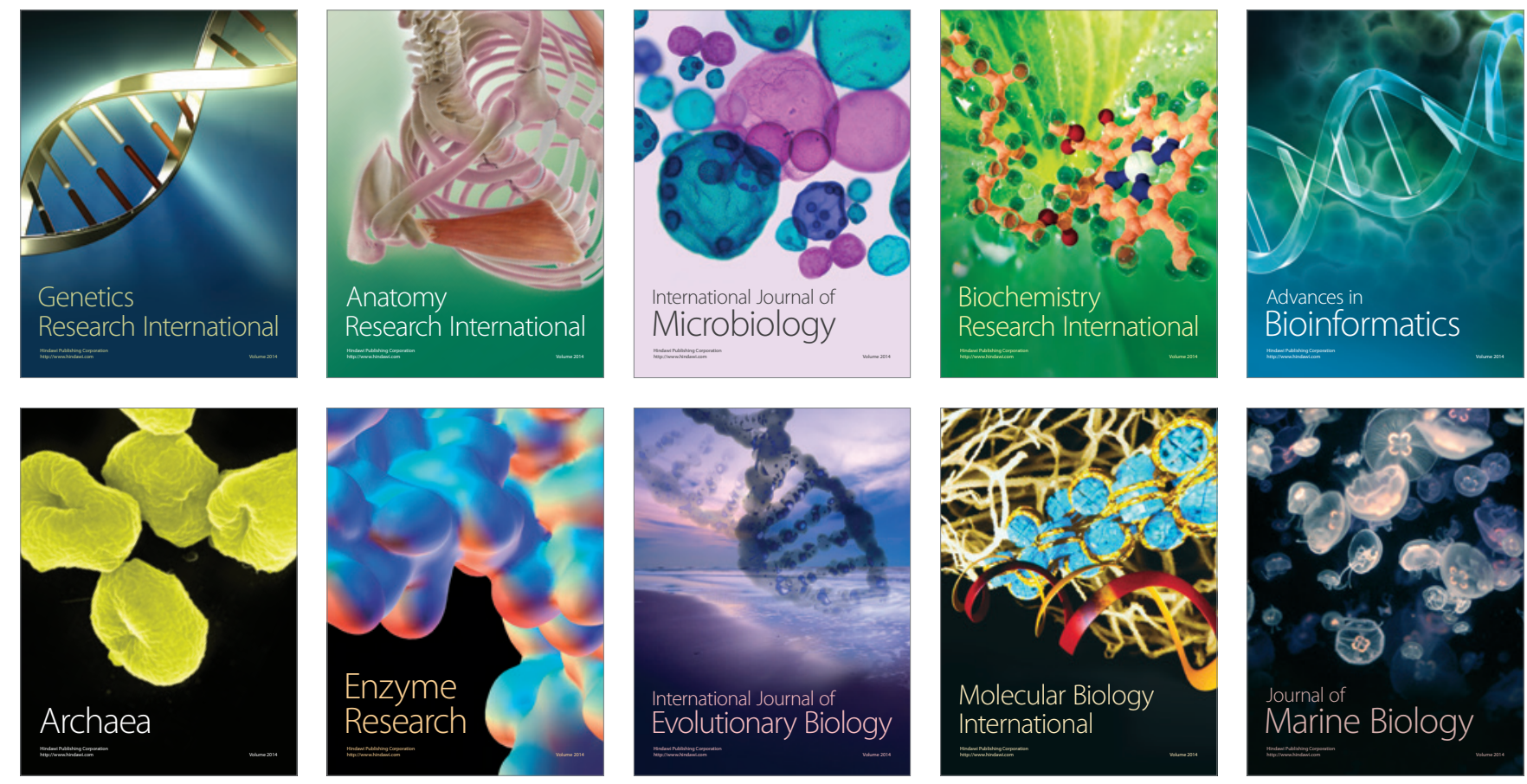